\title{
PRÁTICA POÉTICO-NARRATIVA EM TORNO DE ORPHEU
}

Maria Heloísa Martins Dias ${ }^{\top}$

Recebido: $24 / 10 / 2015$

Aprovado: 27/11/2015

\begin{abstract}
Resumo: O presente texto toma como material fragmentos, versos e passagens de obras de Fernando Pessoa, sobretudo o ortônimo, com o propósito de recriá-los ao inseri-los em novo contexto. O propósito é mostrar como as motivações líricas contidas na "modernidade" proposta pelo poeta português podem se abrir a revisitações criativas, desde que o olhar crítico com elas dialogue. Tal diálogo reforça a importância de uma obra que parece solicitar a intensa participação do leitor como sujeito ativo, participativo e, por que não, também criador. Nesse sentido, pode-se atingir um dos efeitos desejados por Pessoa no conjunto de sua obra: o caráter dramático ou performático de sua poética.
\end{abstract}

Palavras-chave: Fernando Pessoa; lirismo órfico; revisitação crítica; prática criativa.

\section{POETICS AND NARRATIVE PRACTICE AROUND ORPHEU}

\begin{abstract}
The present text utilizes several fragments, passages and verses extracted from Fernando Pessoa's works, specially the orthonimous Pessoa-himself, in order to re-create them in a new context. Our purpose is to show how the liric motives that apear in the "modernity" invented by the Portuguese poet can be revisited by the readers who desire dialogue with this special poetry. Undoubtedly, his work requires the intense participation of the reader because of its complexity and dialogical performance. The reader can be also creator by means of this performatic or dramatic practice - one of the most important purposes of the literary projet of Fernando Pessoa.
\end{abstract}

Keywords: Fernando Pessoa; Orphic lirism; critical revival; creative practice.

Há uma célebre frase de Ítalo Calvino que pode me ajudar a dialogar com Orpheu. Diz Calvino que "um clássico é um livro que nunca terminou de dizer aquilo que tinha para dizer" (CALVINO, 1993, p. 11). Pois bem, podemos ampliar essa afirmação, parafraseando-a e trazendo-a para outro contexto: um movimento literário é aquele processo histórico-literário que nunca terminou de fazer o que tinha para fazer. De fato, penso em Orpheu como uma prática poética que ainda não terminou, porque os apelos e produtos criados por sua geração solicitam de nós uma cumplicidade, pairando como vozes

\footnotetext{
1 Professora Livre-Docente em Literatura Portuguesa, Unesp/São José do Rio Preto, Departamento de Estudos Linguísticos e Literários.
} 


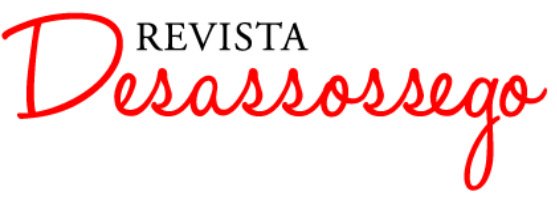

DESASSOSSEGO 14 | DEZ/2015 | ISSN 2175-3180

DOI: http://dx.doi.org/10.11606/issn.2175-3180.v7i14p140-149

que ecoam para além do espaço-tempo em que emergiram. Nesse sentido, penso também em T.S Eliot e Borges, que redefiniram a noção de passado, removendo-o de seu estatuto de acabado ou absoluto para lançá-lo num percurso circular e reversível de modo a tornar passado e presente instâncias que se produzem e se refletem permanentemente. ${ }^{2}$

Por isso, podemos pensar também em uma obra aberta ${ }^{3}$, mas não apenas no sentido de que toda produção o é, oferecendo-se a constantes revisitações e releituras. Não. O sentido de abertura, em Orpheu, é intrínseco à natureza de seu próprio espírito poético, pela maneira como se dão as modulações líricas e narrativas de um canto que se faz em acordes e acordos. Consonâncias. Uma espécie de tecido, feito de muitos fios que se vão entretecendo "e se encorpando em tela, entre todos, / se erguendo tenda, onde entrem todos", como dirá João Cabral em seu famoso poema "Tecendo a manhã”. Assim termina o texto do poeta brasileiro: "A manhã, toldo de um tecido tão aéreo / que, tecido, se eleva por si: luz balão" (MELO NETO, 1979, p. 17-18). A evocação aqui da manhã é mais do que oportuna, se pensarmos nas origens de uma lírica - a dos modernistas portugueses que foi buscar Orfeu como um de seus mitos. Em Cabral, a "lírica" é um tecido sígnico, material. Mas, ao construir a imagem concreta da conjunção de cantos (gritos de galo) para dar vida e forma à manhã, o poeta está retomando uma antiga, certamente mítica, vocação da poesia: a linguagem como acordo entre o homem e o mundo e entre os próprios homens.

Em qualquer tempo e espaço, a poesia se funda sobre essa solicitação de falas cúmplices, seja entre a natureza e o homem, seja entre os próprios sujeitos, seja entre a palavra e a realidade, seja entre os sons e os sentidos, seja entre as imagens. Por isso é sempre atual aquilo que move o canto poético: o desejo de dar ressonância às palavras, revitalizá-las, retirá-las do passado cristalizado, deslocá-las para novas funções.

Fernando Pessoa promoveu esse deslocamento, ao criar produções poéticas situadas em diferentes tempos, dando voz a um eu poliédrico que foi assumindo distintas personagens e encenando diversas situações. Recontextualizou o passado, trazendo para o presente de seu tempo, lançando nova luz no outrora, podendo sê-lo agora. O paganismo

\footnotetext{
${ }^{2}$ De Eliot, cito seu famoso ensaio "Tradition and individual talent", escrito em 1919, e de Borges o instigante texto "Kafka e seus precursores" (1989).

${ }^{3}$ Seria o caso de aproveitarmos o conceito proposto pelo escritor e crítico italiano Umberto Eco, em seu famoso ensaio Opera Aperta, cuja "abertura" equivaleria a uma ambiguidade contida na obra que lhe possibilita uma "relação fruitiva"; isto é, "não a obra-definição, mas o mundo de relações de que esta se origina; não a obraresultado, mas o processo que preside a sua formação" (ECO, 1971, p. 9-10).
} 


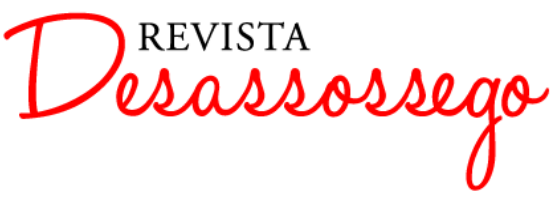

DESASSOSSEGO 14 | DEZ/2015 | ISSN 2175-3180

DOI: http://dx.doi.org/10.11606/issn.2175-3180.v7i14p140-149

grego, figuras latinas, o Egito, o pastoralismo primitivo, filosofias cabalísticas, o cristianismo, personagens da história de Portugal. O Poeta percebeu a intensidade de sua perturbadora sensibilidade que o impedia de se conformar a moldes ou limites, para isso girou sua antena a fim de captar sinais e chamadas longínquas... pôs e retirou a máscara diversas vezes, embarcou em naus, desceu em alcovas profundas, revisitou poetas. É como se Pessoa estivesse nos convidando a fazer o mesmo com suas poesias; percorrê-las é sermos atraídos pela multiplicidade de peças móveis que nunca acabam de formar os mais curiosos painéis ou paisagens e aí reside a grandeza dessa obra-em-processo. Por mais que movimentemos nosso desejo em busca de pistas para decifrar a composição desse universo poético, sempre seremos surpreendidos pelo que não suspeitávamos.

Movida por esse desejo é que me atrevo a recuperar as vozes de Orpheu para criar um espaço poético-narrativo em que elas possam ser redimensionadas em nosso agora.

Num tempo em que Clorindas e Belindas brincavam em suas varandas, Pessoa imergiu numa "Saudade Dada" a repetições infindas.

Tudo era circular, envolvente, e a lira parecia não ter outra função que fazer vibrarem as cordas da inconsciência.

Uma melopeia ${ }^{4}$ obcecada por seu próprio canto, incitando o leitor da poesia a acolher sons aparentemente sem sentido ou sentidos suspensos em esferas inatingíveis.

É um tempo em que o poeta modernista do século XX parece ter despencado como de paraquedas, num repentino "aconteceu-me do alto do infinito / Esta vida", (PESSOA, 1976, p. 127) que ele teria como missão retratar. Retrato rarefeito, bom que se diga, pois plasmado numa tela onde oculta mão, colora alguém que pode ser ou não ser ele mesmo.

Ele mesmo?! Seria ortônimo? Ou heterônimo? No fundo, parece não fazer diferença alguma, pois é impossível identificar esse ser (polim)órfico, que nunca se fixa como uma só pessoa:

Tenho a impressão que as duas figuras se cruzaram na rua, nem então nem

agora,

\footnotetext{
${ }^{4}$ Conceito fundamental para acompanharmos melhor as poesias líricas de Pessoa, a melopeia, tal como Ezra Pound comenta em seu $A b c$ da Literatura (1989), caracteriza-se por uma modalidade de linguagem em que a sonoridade (musicalidade) tecida pelo canto orienta o sentido das palavras.
} 


\begin{abstract}
Mas aqui mesmo, sem tempo a perturbar o cruzamento.
Olhamos indiferentemente um para o outro.

E eu o antigo lá subi a rua imaginando um futuro girassol

E eu o moderno lá desci a rua não imaginando nada. (PESSOA, 1976, p. 386)
\end{abstract}

No ato de se cruzarem pela rua, os dois sujeitos, o antigo (o Caeiro de olhar nítido como o girassol?) e o moderno (o descrente e niilista Álvaro de Campos?), encontram-se numa dimensão atemporal ("nem então nem agora") que anula as distâncias e diferenças entre eu e outro.

Afinal, quem é esse "emissário de um rei desconhecido" (PESSOA, 1976, p. 128) que se julga capaz de encantar ceifeiras, ninfas, deusas, rainhas, pastoras, rios, brisas, folhas, luares, névoas e sombras? Tal desígnio, pairando na indefinição de uma missão singular, só pode se realizar por meio de operações mágicas, aquelas que revelam ser o poeta dotado de uma especialidade, qual a de um mago ou vate ${ }^{5}$.

Roçando sedas pelas horas, desfi(br)ando estranhos ritos e assistindo a cortejos raros, o "poeta em mim que Deus me disse" (PESSOA, 1976, p. 124) não pode ter uma face apenas, e menos ainda faces conhecidas, ele existe somente como linguagem etérea a pairar em sons e imagens de um não-eu.

Espaço propício para sonhos, o carrossel ou comboio de cordas em que Pessoa gira sua emoção acaba por promover efeitos de encantamento, onde não cabe a razão, excluída desse mundo feérico que, no entanto, perturba o poeta. Estranho mundo órfico esse em que o Outro nem sempre é uma presença apaziguadora ou encantatória, como seria próprio desse universo. Há outros eus espreitando o poeta, como presenças ocultas que ele pressente e questiona: "De quem é o olhar / que espreita por meus olhos?", "De onde é que estão olhando para mim? / Que coisas incapazes de olhar estão olhando para mim? / Quem espreita de tudo?”, "Sinto a sua ausência de olhos fitar-me, e estremeço." (PESSOA, 1976, p. 132-133). Seriam as veladoras de O Marinheiro, a estremecerem, sentindo mais presenças do que elas mesmas na sala em que velam a donzela morta?

\footnotetext{
${ }^{5}$ Eis o que nos reporta às primitivas funções da poesia e a um universo em que o papel do poeta se identificava à imagem órfica, ser dotado de poderes capazes de nomear as coisas e fazê-las existirem em uníssono com a fala/canto poético. Octavio Paz (O arco e a lira) e Julio Cortázar ("Para uma poética") trataram dessa afinidade entre o mago e o poeta, cada um a seu modo, porém, convergindo para um propósito comum: mostrar a essência da linguagem poética enquanto criadora da imagem e fundadora do ser, o que corresponde à raiz do modo lírico.
} 
Em meio a silfos, gnomos, deuses, por um lado, e à sua consciência humana pensante, por outro, não é possível ao Pessoa “órfico" ter paz, pois ele existe como joguete de forças desconhecidas.

Nesse tempo irreal, o Poeta erra com sua alma, numa mescla de sonho e realidade, embaralhando os planos com tal intensidade que até as palavras se transformam em peças de um movimento circular:

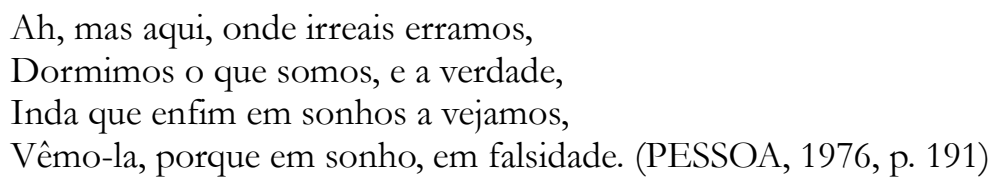

Versos em que parece vagarem também as duas personagens, o eu e sua companheira, pela floresta do alheamento, a viverem "um tempo que não sabia decorrer, [num] espaço para que não havia pensar em poder-se medi-lo.” (PESSOA, 1976, p. 437).

Tempo, em que "o escuro ruído da chuva / é constante em [seu] pensamento", como se chover não acontecesse lá fora e sim no interior do Poeta, uma alma banhada por algas mágoas e pelo ser outonal, pelo rio de sua aldeia, alma sacudida por um terror antigo e insepulto, habitada por grandes mistérios.

Há o desconforto de se sentir impulsionado e em permanente vulnerabilidade: "As minhas ansiedades caem / por uma escada abaixo." (PESSOA, 1976, p. 133). Assim como os cacos do vaso vazio a que o eu lírico de "Apontamento" compara sua alma, caindo "pela escada excessivamente abaixo” (PESSOA, 1976, p. 378), as vozes de Fernando Pessoa e Álvaro de Campos se complementam e parecem reajuntar as peças quebradas de si mesmos. É constante o jogo de reflexos entre essas duas personagens pessoanas, num exercício de dominó poético, como se as peças/versos de um e de outro tentassem buscar equivalências: "Nada sou, nada posso, nada sigo. / Trago, por ilusão, meu ser comigo. / Não compreendo compreender, nem sei / Se hei de ser, sendo nada, o que serei." // "Não sou nada. / Nunca serei nada. / Não posso querer ser nada. / À parte isso, tenho em mim todos os sonhos do mundo.” (PESSOA, 1976, p. 145; p. 362) as faces de Pessoa-ele-mesmo e de Campos se espelham, mas não se juntam.

É um tempo em que ficar na antecâmara, no intervalo, no limiar, em interlúdios, parece ser o espaço ideal para um sujeito que não quer fixar-se nem delimitar-se com contornos nítidos. Espaço povoado simultaneamente de sombras, luzes, névoas, tonalidades esbatidas e impressões cambiantes, passos vagos, velas pandas, tudo a compor 


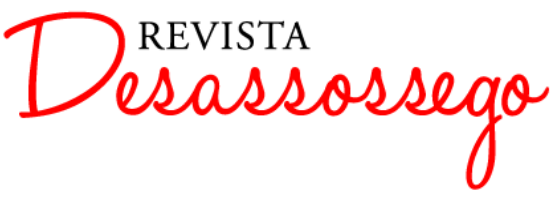

DESASSOSSEGO 14 | DEZ/2015 | ISSN 2175-3180

DOI: http://dx.doi.org/10.11606/issn.2175-3180.v7i14p140-149

uma tela pintada por uma “oculta mão". (PESSOA, 1976, p. 127).

Nesse momento singular em que o poeta se recorta, há a crença (ou o fingimento de uma crença...) de que pode participar de estranhos ritos por meio dos quais sua alma se funde à matéria do mundo: "Caiu chuva em passados que fui eu. / Houve planícies de céu baixo e neve / Nalguma coisa de alma do que é meu.’. Entretanto, essa narrativa iniciática não faz senão concorrer para o não encontro de sentido: "Narrei-me à sombra e não me achei sentido" (PESSOA, 1976, p. 127).

Não há mesmo sentido para uma linguagem cujo propósito é apegar-se à força mágica das palavras, investindo ao máximo nas potencialidades musicais engendradas por elas.

Como se faz intensa a abertura sonora reiterando-se em signos que se espelham por assonâncias e semelhanças!

Nos canais fatais iguais de erradas

As barcas parcas das fadas,

Das fadas aladas e hiemais

E caladas...

Toadas afastadas, irreais, de baladas...

Ais... (PESSOA, 1976, p. 136)

Quão enganosa é essa abertura de sons para o poeta, expressa em signos marcados pelos /as/ e /ais/! É por isso que ele deixa no último verso uma espécie de registro irônico - "Ais" - como lamento pelo absurdo de um canto tão absorto em seus próprios efeitos. Certos poemas se fazem com sons que parecem bater nas paredes de um labirinto sem saída:

\author{
Mas em torno à tarde se entorna \\ A atordoar o ar que arde \\ Que a eterna tarde já não torna! \\ E em tom de atoarda todo o alarde \\ Do adornado ardor transtorna \\ No ar de torpor da tarda tarde. (PESSOA, 1976, p. 134)
}

A obsessão hiperbólica por significantes que atordoam não se faz ingenuamente, mas sim movida pela consciência de que graças a essa exasperação sonora é possível dar forma ao sentido de incômodo diante de um mundo onde Clorindas e Belindas brincam, alheias ao tempo histórico. Nesse contexto, cabe ao poeta flagrar a impossibilidade de se manter o encanto inocente, a não ser pela via da dissonância criada nos signos do título do 


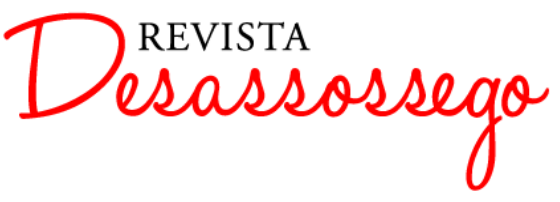

DESASSOSSEGO 14 | DEZ/2015 | ISSN 2175-3180

DOI: http://dx.doi.org/10.11606/issn.2175-3180.v7i14p140-149

poema: "saudade dada" faz ecoar uma cacofonia que aproxima a poesia de certa gratuidade ou ludismo ${ }^{6}$, muito distinto do das meninas alegres nas varandas a brincar de cirandas. Mas isso já seria outra história...

O que podemos indagar é como o poeta pode conter a intensidade do delírio que toma conta de sua mente? Como não sentir dolorosamente a coorte mítica que o assedia?

Talvez a resposta esteja no próprio excesso criado pela poesia, nessa espécie de absurdo ou aparente alheamento para uma arte que faz da desrazão o verdadeiro impulso a movimentá-la.

Talvez o poeta queira ficar sob a "Chuva Oblíqua", curtindo a interpenetração de planos, a obliquidade, as intersecções, enfim, aquela profusão imagética que faria o próprio Orfeu rodopiar perdido no labirinto, sem fio para ajudá-lo a encontrar uma saída, e nem mesmo com as cordas mágicas de sua lira poderia resolver o impasse.

Talvez a "Hora Absurda" seja a única possível para abrigar o poeta e ajudá-lo a decifrar as figuras que desfilam diante de sua enfermidade lírica... Esse doido que estranha a sua própria alma não tem apoio - pontes, terras, paisagens, horizontes - tudo isso se veste de alheamento, tudo é uma tela irreal em que o poeta erra em cor a sua arte...

Imerso em pauis que roçam ânsias em sua alma, Pessoa traça suas "Impressões do Crepúsculo", plenas de reticências e exclamações. Sensações que balouçam, cores esbatidas, mesclas de imagens, suspensões do dizer - um impressionismo simbolista varre o cenário da poesia: "Teu vulto ciciante passa e esquece, / E dia a dia adias para prece / O rito cujo ritmo só decoras...” (PESSOA, 1976, p. 125).

Mesmo na esfera imponderável desse tempo imemorial, há algumas frestas por onde o Poeta consegue ver resíduos de uma realidade concreta, no lá-fora de si mesmo, como o gato que brinca na rua, como se fosse na cama, levando o eu lírico a invejar-lhe a sorte por viver sem pensar, movido apenas por seus "instintos gerais" e sentir só o que sente. (PESSOA, 1976, p. 156). Ou então, o olhar do Poeta se coloca "por trás daquela janela / cuja cortina não muda" (PESSOA, 1976, p. 154), para imaginar a alma que ali se oculta. Mais uma fresta, e o Poeta pode vislumbrar o Natal na província, "nos lares aconchegados, / um sentimento conserva / os sentimentos passados.” (PESSOA, 1976, p.

\footnotetext{
${ }^{6}$ Não seria exagero ver nesse efeito cacofônico a sugestão de um jogo que nos faz lembrar a poética dadaísta, não porque Pessoa tenha pensado em estabelecer diálogo com tal movimento de vanguarda, evidentemente, mas por que o leitor de sua poesia não pode ficar alheio ao panorama mais amplo em que o Modernismo português se insere. Esta é uma das funções da literatura - permitir as inter-relações.
} 


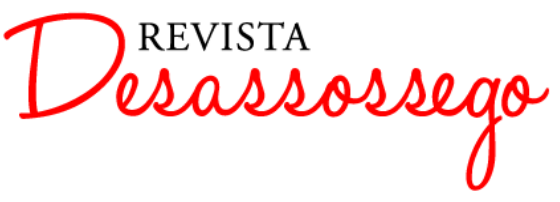

DESASSOSSEGO 14 | DEZ/2015 | ISSN 2175-3180

DOI: http://dx.doi.org/10.11606/issn.2175-3180.v7i14p140-149

148), ou, ainda, pode ver seres que caminham vagamente pela estrada, depois da feira. Por outra fresta aberta por seu pensamento, o Poeta pode partilhar uma infância que não teve, "Quando as crianças brincam / E eu as oiço brincar / Qualquer coisa em minha alma / Começa a se alegrar.” (PESSOA, 1976, p. 169). Alegria que logo se dissipa, no momento em que sua alma se volta, qual um girassol, para o que não está ao pé de si ou para o que não gostaria de ver, como a criança loura que, após um bombardeamento, “jaz no meio da rua (...) as tripas de fora (...) a cara está um feixe/ de sangue e de nada." (PESSOA, 1976, p. 189-190).

Nesse mundo suspenso no tempo e no espaço, os seres boiam, tremulam, vagam, são sonâmbulos, como o "Pierrot Bêbedo" pelas ruas desertas após a feira, sob uma lua que "baqueia (...) deserta e incerta", "na noite entreaberta." (PESSOA, 1976, p. 135). Todo o poema é um oscilar de imagens que se repetem ao longo das quatro estrofes, compondo o cenário de "Ficções do Interlúdio".

É então que a música, ainda que acenando para o poeta certo encantamento, também evoca-lhe acordes impossíveis. Ó tocadora de harpa, baladas de uma outra terra, toadas, o minuete invisível, o trilar de uma flauta, o sino da aldeia, o canto da ceifeira... Há “mais razões p' ra cantar que a vida" (PESSOA, 1976, p. 127), mas não para o poeta atormentado por sua consciência. $\mathrm{O}$ que fazer com todos esses sons que desalinham e arrepiam o seu pensamento? Uma tensão se instala nessa poética, feita de um encantamento estranho, pois não é confortável sentir-se estrangeiro ou rodeado de seres alheios ao próprio eu: "Fantasmas me limitam e me contêm." (PESSOA, 1976, p. 145), que esquisito orfismo é esse que inquieta e desassossega o sujeito lírico? Certamente um orfismo marcado pela consciência do sujeito moderno, em pleno século XX, a simular um reino (im)possível para a poesia dos novos tempos.

Mas ainda não é o momento de fecharmos nosso diálogo com Orpheu.

Para dialogarmos com as vozes de Orpheu é preciso atuar, ao lado das veladoras, como personagens de uma vigília cujas falas e almas se enredam na teia negra que as encobre, é preciso tocar as cordas de uma lira perdida no século XX, à espera de quem possa dar vida às suas notas, acompanhar os passos iniciáticos em direção ao túmulo de Christian Rosencreutz, flagrar o jogo de reflexos entre "Eros e Psiquê", louvar o "Menino da sua mãe" morto pelas malhas tecidas pelo Império.

Entretanto, não basta seguirmos as pegadas das imagens órficas, há que decifrar as 


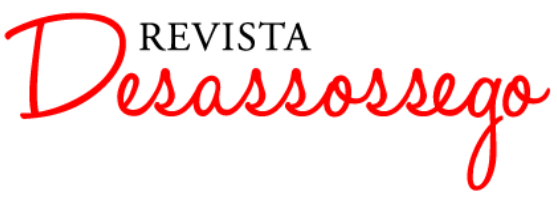

DESASSOSSEGO 14 | DEZ/2015 | ISSN 2175-3180

DOI: http://dx.doi.org/10.11606/issn.2175-3180.v7i14p140-149

estratégias de sua composição, compactuar com o sensacionismo que perpassa os poemas, com o entrecruzamento de planos, com a metafísica de não pensar em nada, com o (des)dobramento autotextual, há que se dispersar como as folhas de um malmequer esquecido, fazer ecoar tautologicamente o discurso.

"Qualquer música" poderia dissolver a incerteza e trazer calma ao interior do poeta, eis o que deseja, mas é um desejo que se perde e ondula como a nota solta e sem sentido, como um canto que se desgarra... "Pobre velha música!" Todas as claves se confundem na pauta inaudita da escrita para onde confluem os tempos: "Fui-o outrora agora." - este o papel da poesia, materializar o impossível através de sua linguagem.

O agora é o momento em que "os Deuses vão-se como forasteiros" e nós homens, como o poeta reconhece, “somos todos palhaços estrangeiros.”. (PESSOA, 1976, p. 193). $\mathrm{Na}$ vida, palco e confusão, a feira desmonta suas barracas e o que se vê das janelas não é o florir de árvores. Agora é o momento em que a música se transforma numa "tênue melodia", uma "forma longínqua e incerta" que o eu não consegue definir, nem afirmar que existe, e cessa: "E agora não há mais música / Do que a dos pinheirais.” (PESSOA, 1976, p. 117).

O encantamento já não atua mais, perdeu-se o poder da varinha que falava às existências essenciais, partilhava das formas naturais e convocava entes mágicos. Pessoa ainda tenta um último sortilégio, sem efeito, porém, porque o tempo já não é para êxtases e alheamentos. O tempo é para ficar frente a frente consigo mesmo, encarar o fingimento, desmascará-lo. Por que autopsicografar-se? Valerá a pena rasurar os grandes mistérios que habitam o limiar do ser? Desejar, como Pessoa, endireitar à força a curva dos horizontes? Ou será melhor tirar a máscara e abrir a fresta para enxergar melhor o universo interior?

O tempo é para deixar de ouvir vozes alheias, é para não pressentir outras presenças, não atuar como veladoras de uma morta misteriosa, não penetrar em florestas de alheamento. O tempo é para não esperar a volta de Sebastiões encobertos pelo mito, é para não acreditar em Césares ou em Cleópatras, é para não ficar desfolhando malmequeres, para não desejar ter os olhos nítidos como um girassol, para não ficar ancorado em permanentes adiamentos.

O tempo é para não ficar inerte, diante da janela, olhando para a tabacaria do outro lado da rua, imerso numa metafísica inútil que somente conduz a um poço sem fundo. Melhor ser como o Esteves sem metafísica. 
É muito o que os novos tempos pedem a Pessoa, porque a tentação de ouvir o passado e falas imemoriais não o abandona. Assim como não o abandonam D. Sebastião e todas as figuras históricas de Mensagem, Cleópatra, Christian Rosencreutz, Gomes Leal, personagens mitológicos, Deus e os deuses, Jesus Cristo... É como se o poeta pudesse cercar de grandes muros esses seres com quem sonha, cultivá-los num jardim bem cuidado, eis o que ele nos convida a fazer, em seu poema "Conselho" (PESSOA, 1976, p. 188).

Conselho em vão, não para si próprio, mas para os que o leem, pois o diálogo fantasmático com os eus e entidades mágicas com os quais convive nessa (ir)realidade órfica não cessa. E não cessa porque, apesar da perplexidade do poeta diante desse mundo que o assombra, há uma aragem que "vem passar a mão sobre o alto da folhagem, e assim nos faz um bem.”. Eis como termina o Cancioneiro.

Sinal de que Pessoa prefere dormir nos braços de Orfeu a abandonar seu regaço. E eu, acabei me entregando também a esse aconchego.

\section{Bibliografia:}

BORGES, Jorge Luís. Outras Inquisições. São Paulo: Globo, 1989.

CALVINO, Ítalo. Por Que Ler os Clássicos. Trad. Nilson Moulin, São Paulo: Companhia das Letras, 1993.

CORTÁZAR, Julio. Valise de Cronópio. Trad. Davi Arrigucci e João Alexandre Barbosa, 2 ed, São Paulo: Perspectiva, 1993, p. 85-101.

ECO, Umberto. Obra Aberta. Trad. Pérola de Carvalho, 2 ed., São Paulo: Perspectiva, 1971.

ELIOT, T.S. Ensaios de Doutrina Crítica. Lisboa: Guimarães, 1997.

MELO NETO, João Cabral. Antologia Poética. 5 ed., Rio de Janeiro: José Olympio, 1979.

PAZ, Octavio. O Arco e a Lira. Trad. Olga Savary, Rio de Janeiro: Nova Fronteira, 1982.

PESSOA, Fernando. Obra Poética. Rio de Janeiro: Nova Aguilar, 1976.

POUND, Ezra. Abc da Literatura. São Paulo: Cultrix, 1989. 